\title{
OPTIMASI BAHAN POLIMER PEMBENTUK MATRIKS TABLET SUSTAINED RELEASE Na. DIKLOFENAK
}

\author{
Audia Triani Olii, Aztriana \\ Fakultas Farmasi Universitas Muslim Indonesia \\ Email : audhee_jie@yahoo.com.
}

\begin{abstract}
Sustained release tablet is one of drug delivery system with an extended release drugs which use polymer to control the release of drug from its dosage form. The advantages of this dosage form is can produce fixed blood levels are without repeat the administration of the unit dose. The aim of this study is to obtain the most optimum polymer as a matrix in sustained release tablets of Diclofenac Sodium. Sustained release tablets made by direct compression method from a mixture of three types of polymer combinations. F1 consists of a combination of HPMC polymer: Etilsellulosa, F2 is the combination of HPMC: Xanthan Gum and F3 consists of a combination of HPMC polymer: Na. Alginate. Each combination of polymer use the same ratio is 1: 2 . Tablet evaluations include the weight uniformity of tablet, size,drug content and dissolution test. Result showed that the most optimum combination of polymer as a sustained release tablet matrix is F1 even F2 have an optimum dissolution.
\end{abstract}

Keyword : Sustained release, Diclofenak sodium, Polymer.

\section{PENDAHULUAN}

Dalam beberapa dekade, pengobatan penyakit akut atau kronik telah dapat ditangani dengan penghantaran obat kepada pasien melalui berbagai bentuk sediaan termasuk tablet, kapsul, pil, suppositoria, krim, salep, larutan, aerosol dan injeksi. Bahkan sistem penghantara obat konvensional tersebut menjadi produk farmasi yang utama, yang sering dijumpai dalam peresepan maupun dijual secara bebas (Chien Y.W, 1992).
Sistem penghantaran obat konvensional diketahui dapat memberikan pelepasan obat yang cepat, meskipun demikian, untuk menjaga agar konsentrasi obat tetap berada dalam batas konsentrasi efektif yang dibutuhkan dalam pengobatan, obat - obatan ini harus diminum beberapa kali dalam sehari. Hal inilah yang menyebabkan level obat dalam tubuh berubah - ubah secara signifikan (Chien Y.W, 1992 ).

Selain itu beberapa obat obatan khususnya yang diberikan 
secara oral atau melaui saluran pencernaan, telah dilaporkan selain dapat dirusak dalam lingkungan asam pada lambung, juga terkadang memberikan efek samping yang sangat tidak menyenangkan kepada pasien. Salah satunya adalah natrium diklofenak yang merupakan obat anti inflamasi dari golongan Anti Inflamasi Nonsteroid atau AINS. Natrium diklofenak cepat diabsorbsi setelah pemberian oral dan mempunyai waktu paruh yang pendek. Obat ini dianjurkan untuk kondisi peradangan kronis seperti artritis rematoid dan osteoartritis serta untuk pengobatan nyeri otot rangka akut. Namun, bahan aktif ini memiliki efek samping yaitu mual, eritema kulit, sakit kepala dan dapat mengiritasi lambung. Pemakaian obat ini harus hati-hati pada penderita tukak lambung (Katzung, 2004 ).

Bentuk sediaan dengan pelepasan diperpanjang atau yang dikenal dengan extended release (ER) didisain untuk membuat obat tersedia dalam waktu yang lama setelah pemberian. Berbagai jenis istilah termasuk sustained release, prolong release dan controlled release digunakan untuk membedakan masing - masing modifikasi bentuk sediaan (Saxena A. et al, 2013). Dengan sistem ini, obat dapat dikontrol pelepasannya dari suatu matrik hingga mencapai target pengobatan dan sekaligus melindungi obat dari lingkungan yang dapat merusak stabilitas obat itu sendiri. Selain itu ,menurut Rao et al, (2001), sistem penghantaran ini mampu mempertahankan kadar terapeutik obat dalam darah atau jaringan selama waktu yang diperpanjang. Keunggulan bentuk sediaan ini menghasilkan kadar obat dalam darah yang merata tanpa perlu mengulangi pemberian unit dosis (Nafsiah, 2009).

Berdasarkan uraian tersebut, maka dibuat suatu formulasi tablet sustained release yang merupakan salah satu bentuk penghantaran obat dengan pelepasan yang diperpanjang, dengan melakukan optimasi terhadap bahan polimer yang digunakan sebagai matriks dan natrium diklofenak sebagai zat aktifnya

\section{METODE PENELITIAN}

\section{Tempat Penelitian}

Penelitian ini dilaksanakan di Laboratorium Farmaseutika Fakultas Farmasi Universitas Muslim Indonesia, Makassar.

\section{Alat dan Bahan}

Alat yang digunakan adalah alat pencetak tablet, Dissolution apparatus, Friabilator, Spektrofotometer UV VIS, Ultraturax, dan alat-alat gelas untuk 
analisis. Sedangkan bahan yang digunakan adalah aquadest, asam asetat, etilsellulosa, HPMC, Alginat, magnesium stearate, NA diklofenak, starch.

\section{Prosedur Kerja}

\section{Pembuatan Tablet Sustained} Release Natrium Diklofenak

Matriks tablet dibuat dengan metode kempa langsung. $\mathrm{Na}$ diklofenak, polimer dan bahan lainnya diayak melewati pengayakan dengan nomor mesh 80. Zat aktif $\mathrm{Na}$ diklofenak, bahan matriks polimer, pengisi, pengikat dan pelincir dicampur hingga homogen kemudian dikempa.

\section{Evaluasi Sistem Penghantaran Obat yang diaktivasi oleh $\mathrm{pH}$}

\section{Evaluasi Tablet}

\section{Keseragaman Bobot}

Keseragaman

bobot dievaluasi dengan menimbang 10 tablet dari masing - masing formula, kemudian dihitung bobot rata - rata tiap tablet. Jika ditimbang satu persatu, tidak boleh satu tabletpun bobotnya menyimpang lebih besar dari bobot rata - rata yang ditetapkan kolom $\mathrm{A}$, dan tidak satu tabletpun yang bobotnya menyimpang lebih besar dari bobot rata -rata yang ditetapkan kolom $\mathrm{B}$ (Depkes RI, 1979).

\section{Keseragaman ukuran}

Sebanyak 10 tablet diukur diameter dan ketebalannya menggunakan jangka sorong. Kecuali dinyatakan lain, diameter tablet tidak lebih dari 3 kali dan tidak kurang dari $11 / 3$ tebal tablet.

\section{Penentuan Kandungan obat}

Kandungan obat dievaluasi dengan cara menimbang 10 tablet dari masing-masing formula, kemudian dihitung berat rata ratanya. Tablet kemudian dihancurkan hingga menjadi serbuk yang halus kemudian ditimbang seberat equivalen dengan $50 \mathrm{mg}$ Natrium Diklofenak, dilarutkan dalam $50 \mathrm{~mL} \mathrm{HCl} \quad 0,1 \mathrm{~N}$ dan dicukupkan dengan aquadest hingga $100 \mathrm{~mL}$. Campuran kemudian diaduk dan dianalisa menggunakan spektrofotemer UVVis pada panjang gelombang 245 nm. Kandungan obat dihitung dengan menggunakan kurva baku.

\section{Uji disolusi}

Matriks tablet ditempatkan pada alat disolusi standar USP. Tes disolusi menggunakan medium larutan $\mathrm{HCl}$ 0,1 $\mathrm{N}$ selama 2 jam kemudian mediumnya diganti dengan dapar asetat $\mathrm{pH}$ 4,5 selama 2 jam. Medium kembali diganti dengan dapar fosfat $\mathrm{pH} 6,8$ hingga 
20 jam. Medium yang digunakan masing - masing sebanyak $900 \mathrm{~mL}$ dengan kecepatan pengadukan sebesar $50 \mathrm{rpm}$ pada temperature $37^{\circ} \mathrm{C} \pm 0,5^{\circ} \mathrm{C} .5 \mathrm{~mL}$ sampel diambil dari $1-20$ jam, setiap kali sampling, medium digantikan dengan jumlah yang sama dari medium yang sama. Larutan sampel kemudian diukur pada spektrofotometer UV VIS pada panjang gelombang $200-300 \mathrm{~nm}$, dan dihitung menggunakan kurva baku.

\section{HASIL PENELITIAN}

Tabel 1. Formulasi tablet sustained release Na Diklofenak menggunakan polimer HPMC, Etil sellulosa, Natrium alginat, Gum xantan.

\begin{tabular}{lccc}
\hline \multicolumn{1}{c}{ Bahan } & F1 $\mathbf{( m g )}$ & F2 $\mathbf{( m g )}$ & F3 $\mathbf{( m g )}$ \\
\hline Natrium Diklofenak & 50 & 50 & 50 \\
HPMC & 31,5 & 31,5 & 31,5 \\
Etil cellulose & 63 & - & - \\
Gum xantan & - & 63 & - \\
Natrium alginate & - & - & 63 \\
Mg. Stearate & 0,5 & 0,5 & 0,5 \\
Aerosil & 0,5 & 0,5 & 0,5 \\
Laktosa & 5 & 5 & 5 \\
\hline
\end{tabular}

\section{Keseragaman Bobot Tablet}

Tabel 2. Berat rata - rata formula sustained release Na Diklofenak

\begin{tabular}{cc}
\hline Formula & Berat rata - rata $(\mathbf{m g})$ \\
\hline F1 & 251,57 \\
F2 & 351,07 \\
F3 & 288,42 \\
\hline
\end{tabular}

\section{Keseragaman Ukuran Tablet}

Tabel 3. Ukuran rata - rata diameter dan ketebalan tablet sustained release $\mathrm{Na}$ Diklofenak

\begin{tabular}{ccc}
\hline Formula & Rata- rata diameter $(\mathbf{m m})$ & Rata -rata ketebalan $(\mathbf{m m})$ \\
F1 & 3,1 & 1,8 \\
F2 & 3,1 & 2,01 \\
F3 & 3,1 & 1,98 \\
\hline
\end{tabular}

\section{Kandungan Obat}

Kandungan obat dari tablet sustained release dievaluasi dengan menimbang 10 tablet sustained release dan dihitung berat rata- ratanya. Tablet kemudian dihaluskan dan ditimbang dengan berat yang equivalen dengan $50 \mathrm{mg}$ Natrium Diklofenak. Pengukuran dilakukan dengan 
spektrofotometer UV-VIS dengan diperoleh dapat dilihat pada tabel medium pelarut $\mathrm{HCl} 0,1 \mathrm{~N}$. Hasil yang berikut :

Tabel 4. Kandungan obat dari masing - masing formula tablet sustained release Natrium Diklofenak.

\begin{tabular}{cc}
\hline Formula & Kandungan obat (\%) \\
\hline F1 & 99,94 \\
F2 & 97,35 \\
F3 & 97,66 \\
\hline
\end{tabular}

\section{Uji Disolusi}

Tabel 5. Hasil pengukuran absorban Tablet Sustained Release Formula 1 dalam media disolusi $\mathrm{HCl} 0,1 \mathrm{~N} \mathrm{pH} \mathrm{1,2,} \mathrm{dapar} \mathrm{Asetat} \mathrm{pH} 4,5$ dan dapar fosfat $\mathrm{pH}$ 6,8

\begin{tabular}{|c|c|c|c|c|c|c|c|c|}
\hline \multirow{2}{*}{ Medium } & \multirow{2}{*}{$\begin{array}{c}\text { Waktu } \\
\text { (jam) }\end{array}$} & \multicolumn{3}{|c|}{ Repitasi } & \multirow{2}{*}{ Rata-rata } & \multirow{2}{*}{ SD } & \multirow{2}{*}{$\begin{array}{c}\% \\
\text { disolusi }\end{array}$} & \multirow{2}{*}{$\begin{array}{c}\% \\
\text { kumulatif }\end{array}$} \\
\hline & & 1 & 2 & 3 & & & & \\
\hline \multirow{3}{*}{$\mathrm{HCl}$} & 0 & 0.003 & 0.002 & 0.012 & 0.00567 & 0.0055 & 6.32299 & 6.32299 \\
\hline & 1 & 0.023 & 0.021 & 0.018 & 2067 & 0.00 & 9.04196 & 15.3649 \\
\hline & 2 & 0.028 & 0.034 & 0.066 & & & 98 & 947 \\
\hline \multirow{2}{*}{ Asetat } & 3 & 0.021 & 0.016 & 0.01 & 0.01567 & 0.0055 & 4.44071 & 32.8354 \\
\hline & 4 & 0.012 & 0.013 & 0.015 & 0.01333 & 0.0015 & 4.18228 & 37.0177 \\
\hline \multirow{3}{*}{ Fosfat } & 6 & 0.022 & 0.025 & 0.019 & 0.022 & 0.003 & 0.21052 & 37.2282 \\
\hline & 8 & 0.047 & 0.049 & 0.044 & 0.04667 & 0.0025 & 1.90514 & 39.1334 \\
\hline & 10 & 0.058 & 0.054 & 0.059 & 0.057 & 0.0026 & 2.79142 & 41.9248 \\
\hline
\end{tabular}

Tabel 6. Hasil pengukuran absorban Tablet Sustained Release Formula 2 dalam media disolusi $\mathrm{HCl} 0,1 \mathrm{~N} \mathrm{pH} \mathrm{1,2,} \mathrm{dapar} \mathrm{Asetat} \mathrm{pH} 4,5$ dan dapar fosfat $\mathrm{pH}$ 6,8

\begin{tabular}{|c|c|c|c|c|c|c|c|c|}
\hline \multirow{2}{*}{ Medium } & \multirow{2}{*}{$\begin{array}{l}\text { Waktu } \\
\text { (jam) }\end{array}$} & \multicolumn{3}{|c|}{ Repitasi } & \multirow{2}{*}{ Rata-rata } & \multirow{2}{*}{ SD } & \multirow{2}{*}{$\begin{array}{c}\% \\
\text { disolusi }\end{array}$} & \multirow{2}{*}{$\begin{array}{c}\% \\
\text { kumulatif }\end{array}$} \\
\hline & & 1 & 2 & 3 & & & & \\
\hline \multirow{3}{*}{$\mathrm{HCl}$} & 0 & 0.007 & 0.006 & 0.008 & 0.007 & 0.001 & 6.56468 & 6.56468 \\
\hline & 1 & 0.012 & 0.018 & 0.019 & 0.01633 & 0.0038 & 8.25648 & 14.8212 \\
\hline & 2 & 0.024 & 0.023 & 0.02 & 0.02233 & 0.0021 & 9.34406 & 24.1652 \\
\hline \multirow{2}{*}{ Asetat } & 3 & 0.019 & 0.013 & 0.011 & 0.01433 & 0.0042 & 4.29303 & 28.4582 \\
\hline & 4 & 0.02 & 0.024 & 0.021 & 0.02167 & 0.0021 & 5.10525 & 33.5635 \\
\hline \multirow{6}{*}{ Fosfat } & 6 & 0.061 & 0.052 & 0.057 & 0.05667 & 0.0045 & 2.76283 & 36.3263 \\
\hline & 8 & 0.098 & 0.102 & 0.098 & 0.09933 & 0.0023 & 6.42351 & 42.7498 \\
\hline & 10 & 0.126 & 0.128 & 0.123 & 0.12567 & 0.0025 & 8.68096 & 51.4308 \\
\hline & 12 & 0.155 & 0.153 & 0.15 & 0.15267 & 0.0025 & 10.9967 & 62.4275 \\
\hline & 16 & 0.2 & 0.2 & 0.198 & 0.19933 & 0.0012 & 14.9993 & 77.4269 \\
\hline & 20 & 0.214 & 0.221 & 0.217 & 0.21733 & 0.0035 & 16.5432 & 93.9701 \\
\hline
\end{tabular}


Tabel 7. Hasil pengukuran absorban Tablet Sustained Release Formula 3 dalam media disolusi $\mathrm{HCl} 0,1 \mathrm{~N} \mathrm{pH} \mathrm{1,2,} \mathrm{dapar} \mathrm{Asetat} \mathrm{pH} 4,5$ dan dapar fosfat $\mathrm{pH}$ 6,8

\begin{tabular}{|c|c|c|c|c|c|c|c|c|}
\hline \multirow{2}{*}{ Medium } & \multirow{2}{*}{$\begin{array}{l}\text { Waktu } \\
\text { (jam) }\end{array}$} & \multicolumn{3}{|c|}{ Repitasi } & \multirow{2}{*}{ Rata-rata } & \multirow{2}{*}{ SD } & \multirow{2}{*}{$\begin{array}{c}\% \\
\text { disolusi }\end{array}$} & \multirow{2}{*}{$\begin{array}{c}\% \\
\text { kumulatif }\end{array}$} \\
\hline & & 1 & 2 & 3 & & & & \\
\hline \multirow{3}{*}{$\mathrm{HCl}$} & 0 & 0.006 & 0.004 & 0.014 & 0008 & 0.0053 & 6.74594 & 6.74594 \\
\hline & 1 & 0.017 & 0.017 & 0.016 & & & 8.3169 & 15.0628 \\
\hline & 2 & 0.025 & 0.019 & 0.021 & & & 9.22322 & 24.2861 \\
\hline \multirow{2}{*}{ Asetat } & 3 & 0.003 & 0 & 0.002 & & & 2.66859 & 26.9547 \\
\hline & 4 & 0.01 & 0.009 & 0.005 & & & 3.59157 & 30.5462 \\
\hline \multirow{6}{*}{ Fosfat } & 6 & 0.011 & 0.014 & 0.01 & & & 1.09681 & 31.643 \\
\hline & 8 & 0.039 & 0.0 & 0.04 & & & 1.13321 & 32.7762 \\
\hline & 10 & 0.036 & 0.039 & 0.026 & & 0.00 & 0.79013 & 33.5664 \\
\hline & 12 & 0.057 & 0.062 & 0.053 & 0.0 & 0.0045 & 2.82001 & 36.3864 \\
\hline & 16 & 0.076 & 0.074 & 0.07 & & & 4.36387 & 40.7503 \\
\hline & 20 & 0.107 & 0.101 & 0.114 & 0.10733 & 0.0065 & 7.10851 & 47.8588 \\
\hline
\end{tabular}

Keterangan :

Jam ke 0-2 = Medium $\mathrm{HCl}$

Jam ke 3-4 = Dapar Asetat

Jam ke 6-20 = Dapar Fosfat

\section{PEMBAHASAN}

Evaluasi keseragaman bobot menunjukkan bahwa F1 memiliki bobot rata - rata tablet sebesar 251,57, F2 dan F2 masing - masing secara berurutan sebesar $351,07 \mathrm{mg}$ dan 288,42 mg. hasil ini menunjukkan bahwa formula yang paling sesuai bobotnya dengan yang diharapkan yaitu masing - masing tablet seberat $250 \mathrm{mg}$ ekuivalen dengan $50 \mathrm{mg} \mathrm{Na}$. Diklofenak adalah formula 1 atau F1. Bobot yang meningkatkan dari bobot tablet yang diharapkan disebabkan karena daya kompresibilitas dari bahan polimer sangat tinggi sehingga ketika dikempa, volumenya bertambah. Evaluasi yang selanjutnya adalah evaluasi keseragaman ukuran.
Dari hasil yang diperoleh diketahui bahwa $\mathrm{F} 1$ memiliki diameter $3,1 \mathrm{~mm}$ dan ketebalan 1,8 mm, F2 memiliki diameter 3,1 mm dan ketebalan 2,01 $\mathrm{mm}$ dan F3 memiliki diameter $3,1 \mathrm{~mm}$ dengan ketebalan 1,98 mm.

Hasil analisa menggunakan spktrofotometer UV - Vis pada panjang gelombang $245 \mathrm{~nm}$, menunjukkan bahwa kandungan obat pada F1 sebesar 99,94 \%, F2 sebesara 97,35 \% dan F3 sebesar $97,66 \%$. Hal ini menunjukkan bahwa pada F1 obat dapat terlepas dengan baik dari matriks tablet sehingga obat siap diabsorpsi sesuai dengan dosis terapinya. Secara umum matriks adalah bahan dasar pembentuk komposit yang mengikat pengisi tanpa 
melibatkan ikatan kimia. Matriks dari polimer berperan untuk mempertahankan posisi dan orientasi serat untuk melindunginya dari lingkungan. Selain itu, kombinasi matriks polimer yang bersifat hidrofilik dan lipofilik menyebabkan pelepasan obat dari matriks terjadi secara perlahan - lahan sehingga level obat dapat dipertahankan dalam periode waktu tertentu. Mekanisme pelapasan obat terjadi dengan adanya difusi terkentrol bahan obat dari matriks polimer karena adanya cairan di lingkungan tubuh atau dalam hal ini cairan lambung dan usus.

Adapun hasil pengujian disolusi menunjukan bahwa pelepasan obat dari ketiga formula yang dilakukan selama 20 jam sangat lambat dimana pada $\mathrm{FI}$ jumlah obat yang terdisolusi adalah sebanyak 55,702\%, F2 sebanyak $93,970 \%$ dan F3 sebanyak $47,858 \%$. Pada F3, jumlah obat yang terlepas lebih sedikit dibandingkan dengan F1 dan F2. Hal ini menunjukan bahwa Gum Xantan yang bersifat anionik akan lebih memperlambat pelepasan obat jika dikombinasikan dengan HPMC karena Gum Xantan dapat memperkecil pelepasan awal yang terjadi, ini disebabkan karena Gum Xantan lebih mudah terhidrasi dalam air dibandingkan dengan HPMC (Pratiwi M., 2010) .

\section{KESIMPULAN}

Berdasarkan hasil penelitian yang diperoleh diketahui bahwa matriks tablet Sustained Release yang memberikan hasil evaluasi tablet dan kandungan obat yang paling optimum adalah $\mathrm{F} 1$ yaitu formula tablet Sustained Release yang menggunakan kombinasi polimer HPMC : Etilsellulosa dengan perbandingan 1:2 . Adapun F2 menunjukkan hasil disolusi yang paling optimum yaitu sebesar $93,970 \%$.

\section{DAFTAR PUSTAKA}

Chien, Y.W., 1992, Novel Drug Delivery System Second Edition, Revised and Expanded, Marcel Dekker Inc. New York.

DepKes. RI., 1979 : Farmakope Indonesia ed. 3, Departemen Kesehatan Republik Indonesia, $6-7$.

DepKes. RI., 1995 : Farmakope Indonesia ed. 4, Departemen Kesehatan Republik Indonesia, 107-108, 771, 999, 1143.

Katzung, B.G., 2001 : Farmakologi: Dasar dan Klinik, edisi 2, Penerbit Salemba Medika, Jakarta, p. 420.

Nafsiah, 2009, Formulasi Sediaan Lepas Lambat Tablet Teofilin Dengan Matriks Natrium Carboxymetil Cellulose Dan Avicel Ph 102 Dengan Metode Granulasi Basah, Surakarta. 
Optimasi Bahan Polimer Pembentuk Matriks Tablet Sustained Release Na. Diklofenak

Saxena A., Srinivas, Sravanthi, 2013:

Paliperidone, Innovation in

Formulation and In - Vitro

Pharmaceuticals

and

Evaluation of Matrix Type

Pharmacotherapy,1(3), 185-

Sustained Release Tablets of 198. 